\section{Discussion}

Despite the increase in our knowledge and understanding of the pathogenic mechanisms present in patients with diffuse toxic goitre-particularly since the discovery of LATS (Adams, 1958) and its characterization as anmunoglobulin (Adams and Kennedy, 1962; McKenzie, 1962; Kriss et al., 1964; Dorrington et al., 1966)-the cause of the abnormal thyroid function in this disease has remained uncertain. The simplest explanation, and the only one which accounts for the phenomenon of neonatal thyrotoxicosis, is that there is a circulating humoral stimulator acting upon the gland (McKenzie, 1972). Thyrotrophin has been excluded from this role by the fact that its level in blood is less than normal in diffuse toxic goitre (Adams et al., 1969). To many workers LATS has been unacceptable as a causative agent because it is undetectable in many cases and the level in any individual patient does not correlate with the degree of abnormal thyroid function (Volpe et al., 1972). LATS protector, however, meets two criteria not fulfilled by LATS; our evidence confirms the high incidence of LATS protector in diffuse toxic goitre and shows that its serum level correlates well with early thyroid ${ }^{131}$ I uptake. Furthermore, LATS protector has been shown to stimulate the human thyroid, both in vitro (Shishiba et al., 1973) and in vivo (Adams et al., 1974). We therefore think that in LATS-negative patients with diffuse toxic goitre LATS protector is the pathogenic agent.

The question whether LATS protector is present in every case of diffuse toxic goitre remains open. It was not found in five of the 50 patients studied, but all these were relatively mild cases with normal or only slightly raised thyroid ${ }^{131}$ I uptake and large goitres. Failure to detect LATS protector in these inactive cases may have been due to assay insensitivity, but incorrect diagnosis of thyrotoxicosis or an alternative pathogenic mechanism for thyroid dysfunction are other possible explanations.
The pathogenesis of the ophthalmopathy of Graves's disease remains less well understood than the pathogenesis of thyrotoxicosis. We found no significant correlation between the class of ophthalmopathy and the LATS protector level. The highest incidence of infiltrative ophthalmopathy, however, was observed in the group of patients with both LATS and LATS protector, and the lowest incidence was in those patients in whom neither immunoglobulin çould be detected. Our findings support the view that LATS protector and ophthalmopathy may be associated in Graves's disease but the relation is not a causal one.

We thank Mr. W. S. Cague for skilled technical help.

Requests for reprints should be addressed to Dr. R. D. H. Stewart.

\section{References}

Adams, D. D. (1958). Fournal of Clinical Endocrinology and Metabolism, 18, 699

Adams, D. D., et al. (1974). Journal of Clinical Endocrinology and Metabolism. In press.

Adams, D. D., and Kennedy, T. H. (1962). Proceedings of the University of Otago Medical School, 40, 6.

Adams, D. D., and Kennedy, T. H. (1967). fournal of Clinical Endocrinology and Metabolism, 27, 173.

Adams, D. D., and Kennedy, T. H. (1971). Fournal of Clinical Endocrinology and Metabolism, 33, 47

Adams, D. D., Kennedy, T. H., and Purves, H. D. (1969). Fournal of Clinical Endocrinology and Metabolism, 29, 900.

Clark, F., and Horn, D. B. (1965). Fournal of Clinical Endocrinolgy and Metabolism, 25, 39.

Dorrington, K. J., Carneiro, L., and Munro, D. S. (1966). Biochemical fournal, $98,858$.

Kriss, J. P., Pleshakov, V., and Chien, J. R. (1964). fournal of Clinical Endocrinology and Metabolism, 24, 1005

McKenzie, J. M. (1962). Fournal of Biological Chemistry, 237, 3571.

McKenzie, J. M. (1972). Metabolism, 21, 883.

Oddie T H Meschan I, and Wortham, J. (1955). Fournal of Clinical Investigation, 34, 106.

Shishiba, Y., Shimizu, T., Yoshimura, S., and Shizume, K. (1973). fournal of Clinical Endocrinology and Metabolism, 36, 517.

Volpe, R., Edmonds, M., Lamki, L., Clarke, P. V., and Row, V. V. (1972) Mayo Clinic Proceedings, 47, 824.
Ma.,

Werner, S. C. (1969). Fournal of Clinical Endocrinology and Metabolism, 29, 982.

\title{
Respiratory Symptoms in Children and Parental Smoking and Phlegm Production
}

\author{
J. R. T. COLLEY
}

British Medical fournal, 1974, 2, 201-204

\section{Summary}

A study of respiratory symptoms in 2,426 schoolchildren aged 6-14 years was carried out in Aylesbury, Buckinghamshire, in 1971. The prevalence of cough in the children was associated with the parents' smoking habits; prevalence was lowest where both parents were non-smokers, highest where both parents smoked, and lay between these two levels where only one parent smoked. A close association was found between parents' and children's respiratory symptoms that was independent of parents' smoking habits. There was no suggestion that exposure to the cigarette smoke generated when parents smoked had any more than a small effect upon the child's respiratory symptoms. While the sharing of genetic susceptibility between parents and children is a factor, therefore, cross infection, particularly in the families where parents smoke, is an important element in the association.

Department of Medical Statistics and Epidemiology, London School of Hygiene and Tropical Medicine, London WC1E 7HT

J. R. T. COLLEY, M.D., M.F.C.M., Senior Lecturer in Epidemiology

\section{Introduction}

Norman-Taylor and Dickinson (1972) suggested that children with parents who smoke may be at particular risk from respiratory disease. These authors were not, however, explicit about the nature of the risk. They implied that exposure of children to cigarette smoke at home might increase the risk of respiratory illness. This paper reports the findings of a study in which the nature of the association between parental smoking and respiratory disease in their children was investigated.

\section{Methods}

The material was collected during a study of the prevalence of respiratory disease in schoolchildren and their parents in Aylesbury, Buckinghamshire, in 1971. The population consisted of all children aged 6-14 years attending seven schools in Aylesbury-a total of 2,598 children (1,328 boys and 1,270 girls). Data were collected on 2,426 children and their parents, a response rate of $93.4 \%$.

A self-administered questionnaire was completed by the parents, who answered questions about their own and their 
children's health. The relevant questions were: (a) for each child, Does he/she usually cough during the day or at night in the winter?; (b) for each parent, (1) Do you usually bring up any phlegm from your chest first thing in the morning in winter?; ( 2 a) Do you smoke? If "No"; $(2 b)$ Have you ever smoked as much as one cigarette a day for as long as a year? Parents who answered "Yes" to question $(2 a)$ were classified as smokers. They were also asked how many cigarettes they smoked a day, how many ounces of tobacco they smoked each week, and how many cigars, large and small, they smoked each week. Those parents that answered "No" to question ( $2 a)$ and answered question ( $2 b$ ) in the negative were classified as non-smokers, while those that responded in the affirmative to question ( $2 b$ ) were classified as ex-smokers. The validity of the question on cough in the children when used in a self-administered questionnaire has already been established (Colley and Reid, 1970), as has that of the question on phlegm production (Krueger et al., 1970).

The father was asked about his occupation and from this his social class was obtained. (Classification of Occupation, 1970). The number of siblings which the index ahild had was also recorded.

\section{Results}

The relation in the parents between smoking habits and prevalence of phlegm was what one would have expected; prevalence rose with amount smoked. Parents were classified by smoking habit into five groups; group 1, both parents nonsmokers; group 2, one parent a smoker, the other a nonsmoker; group 3, both parents smokers; group 4, both parents ex-smokers or one an ex-smoker and the other a non-smoker or smoker; and group 5, one or both parents gave no data on smoking habits. Within these five groups the prevalence in the children of cough during the day or at night in the winter was determined (table I). The cough prevalence rates were lowest in children with one or both parents ex-smokers. The gradient in prevalence over groups 1,2 , and 3 was statistically significant $\left(\chi^{2}\right.$ for trend $\left.6.865 ; 0.01>P>0.005\right)$. The findings indicated an association between parental smoking habits and the prevalence of symptoms in their children.

The analysis was taken a stage further by classifying parents by both smoking habits and by.their response to the question, Do you usually bring up any phlegm from your chest first thing in the morning in winter? (table II). Within each group the prevalence of cough in children was lowest among children of parents who did not report symptoms. It was highest in those children where both parents reported symptoms. Where only one parent reported the symptom the prevalence rate lay between these two extremes. Overall, there was a threefold difference in prevalence of cough between children with neither parent having the symptoms and both having the symptom.

Some of the prevalence rates in table II were based on small numbers, but the numbers in the category where neither parent had symptoms allowed a firmer conclusion. It was thus interesting to note that in this category the prevalence of cough rose from $12.4 \%$ in children of non-smoking parents to $14.3 \%$ where one parent smoked and to $14.7 \%$ where both smoked. This trend while small and not statistically significant nevertheless raised the possibility that exposure to cigarette smoke at home when parents smoked might have had some effect on the child's respiratory tract. A more precise estimate of the effects of "passive smoking" by the child was obtained by estimating the maximum daily exposure of the child to their parents' cigarette smoke. This was derived by the addition of both parents' daily cigarette consumption. Among the children of parents who did not have morning phlegm there was a small gradient for cough prevalence according to the number of cigarettes (or tobacco equivalent) smoked by the parents (table III). This gradient in prevalence is not, however, statistically significant $\left(\chi^{2}\right.$ trend $1 \cdot 36 ; 0.30>\mathrm{P}>0.20)$.

TABLE I-Prevalence of Cough during Day or at Night in Winter in Children aged 6-14 according to Parents' Smoking Habits

\begin{tabular}{l|c|c|c|c|c|}
\hline & & \multicolumn{2}{|c|}{ Parents' Smoking Group* } \\
\cline { 2 - 4 } & Percentage (No.) of children with cough & 1 & 2 & 3 & 4 \\
\hline $15 \cdot 6(320)$ & $17 \cdot 7(547)$ & $22 \cdot 2(634)$ & $14 \cdot 2(620)$ & $20 \cdot 7(217)$ & $18 \cdot 0(2,338)$ \\
\hline
\end{tabular}

* See text for composition of groups.
tTotal excl udes 88 children for whom there were no data on cough.

TABLE II-Prevalence of Cough during Day or at Night in Winter in Children aged 6-14 according to Parents Smoking Habits and Presence of Winter Morning Phlegm

\begin{tabular}{|c|c|c|c|c|c|c|c|c|c|c|c|c|c|c|c|}
\hline \multirow[b]{2}{*}{$\begin{array}{l}\text { Winter morning phlegm } \\
\text { in parents }\end{array}$} & \multicolumn{3}{|c|}{ Group 1} & \multicolumn{3}{|c|}{ Group 2} & \multicolumn{3}{|c|}{ Group 3} & \multicolumn{3}{|c|}{ Group 4} & \multicolumn{3}{|c|}{ Total* } \\
\hline & Neither & One & Both & Neither & One & Both & Neither & One & Both & Neither & One & Both & Neither & One & Both \\
\hline $\begin{array}{l}\text { Percentage (No.) of } \\
\text { children with cough.. }\end{array}$ & $\begin{array}{l}12 \cdot 4 \\
(274)\end{array}$ & $\begin{array}{l}27.5 \\
(40)\end{array}$ & $\begin{array}{l}80 \cdot 0 \\
(5)\end{array}$ & $\begin{array}{l}14 \cdot 3 \\
(420)\end{array}$ & $\begin{array}{l}24 \cdot 7 \\
(97)\end{array}$ & $\begin{array}{l}52.9 \\
(17)\end{array}$ & $\begin{array}{l}14 \cdot 7 \\
(389)\end{array}$ & $\begin{array}{l}28 \cdot 3 \\
(159)\end{array}$ & $\begin{array}{l}43 \cdot 5 \\
(69)\end{array}$ & $\begin{array}{l}12 \cdot 6 \\
(499)\end{array}$ & $\begin{array}{l}19 \cdot 4 \\
(98)\end{array}$ & $\begin{array}{l}23 \cdot 1 \\
(13)\end{array}$ & $\begin{array}{c}13 \cdot 5 \\
(1,582)\end{array}$ & $\begin{array}{l}25 \cdot 1 \\
(394)\end{array}$ & $\begin{array}{l}44 \cdot 2 \\
(104)\end{array}$ \\
\hline
\end{tabular}

*Total excludes 346 children for whom there were no data on cough or parents' smoking habits or morning phlegm.

TABLE III-Prevalence of Cough during Day or at Night in Winter in Children aged 6-14 according to Parents Smoking Habits, Number of Cigarettes smoked, and Presence of Winter Morning Phlegm

\begin{tabular}{|c|c|c|c|c|c|c|c|c|c|c|c|c|c|c|}
\hline \multirow{4}{*}{ Winter morning phlegm in parents } & \multirow{3}{*}{\multicolumn{2}{|c|}{ Group 1}} & \multicolumn{8}{|c|}{ Groups 2 and 3} & \multirow{3}{*}{\multicolumn{2}{|c|}{ Group 4}} & \multirow{3}{*}{\multicolumn{2}{|c|}{ Total $\dagger$}} \\
\hline & & & & & Total N & f Cige & es* & & & & & & & \\
\hline & & & \multicolumn{2}{|c|}{$1-9$} & \multicolumn{2}{|c|}{$10-19$} & \multicolumn{2}{|c|}{$20-29$} & \multicolumn{2}{|c|}{$\geqslant 30$} & & & & \\
\hline & $\mathbf{N}$ & $\mathbf{O} / \mathbf{B}$ & $\mathbf{N}$ & O/B & $\mathbf{N}$ & O/B & $\mathbf{N}$ & $\mathbf{O} / \mathbf{B}$ & $\mathbf{N}$ & O/B & $\mathbf{N}$ & O/B & $\mathbf{N}$ & O/B \\
\hline $\begin{array}{c}\text { Percentage (No.) of children with } \\
\text { cough }\end{array}$ & $\begin{array}{l}12 \cdot 4 \\
(274)\end{array}$ & $\begin{array}{l}33 \cdot 3 \\
(45)\end{array}$ & $\begin{array}{l}13 \cdot 3 \\
(135)\end{array}$ & $\begin{array}{l}32 \cdot 1 \\
(28)\end{array}$ & $\begin{array}{l}13 \cdot 8 \\
(247)\end{array}$ & $\begin{array}{l}21.5 \\
(65)\end{array}$ & $\begin{array}{l}14 \cdot 9 \\
(208)\end{array}$ & $\begin{array}{l}37 \cdot 8 \\
(74)\end{array}$ & $\begin{array}{l}15 \cdot 9 \\
(208)\end{array}$ & $\begin{array}{l}32 \cdot 2 \\
(174)\end{array}$ & $\begin{array}{l}12 \cdot 6 \\
(499)\end{array}$ & $\begin{array}{l}19 \cdot 8 \\
(111)\end{array}$ & $\begin{array}{r}13 \cdot 56 \\
(1,571)\end{array}$ & $\begin{array}{l}28 \cdot 97 \\
(497)\end{array}$ \\
\hline
\end{tabular}

$\mathrm{N}=$ Neither. $\mathrm{O} / \mathrm{B}=$ One or both.

'Total excludes 358 children for whom there were no data on cough or parents' smoking habits or morning phlegm. 
Several points have to be considered in interpreting these findings. As in other studies (Holland et al., 1969; Colley and Reid, 1970), social class gradients for respiratory symptoms in children were found in this series. Children with fathers in semi-skilled and unskilled occupations had higher prevalence rates for respiratory symptoms than those whose fathers were in skilled or non-manual occupations. A concentration of low social class families in the groups where both parents reported winter morning phlegm could have produced a similar pattern to that shown in table II. That this could not have accounted for the observed patterns of cough prevalance in the children may be seen in table IV, where cough prevalence is given for children in social class III according to the parents' history of phlegm production after standardization for smoking. Cough prevalence in the children increased, as before, with the presence of parental phlegm production.

TABLE IV-Prevalence in Social Class III of Cough during Day or at Night in Winter in Children aged 6-14 according to Parents Phlegm (Standardized for Parents' Smoking Habits)

\begin{tabular}{ll|l|l|l}
\hline Parents with winter morning phlegm & $\ldots$ & Neither & One & Both \\
\hline Percentage (No.) of children with cough & $\ldots$ & $15 \cdot 4(824)$ & $27 \cdot 4(207)$ & $52 \cdot 9(54)$
\end{tabular}

Children from large families have higher prevalence rates for respiratory symptoms than those from small families (Colley, 1970), and a concentration of large families in the groups of parents with symptoms might also have resulted in the prevalence of morning cough being similar to that shown in table II. It can be seen from table V, however, that within families of similar size the same gradients for cough prevalence according to parents' phlegm production were present, indicating that differences in the number of siblings could not have explained the gradient in cough prevalence.

TABLE v-Prevalence of Cough during Day or at Night in Winter in Children aged 6-14 according to Parents' Phlegm and Number of Siblings (Standardized for Parents' Smoking Habits)

\begin{tabular}{|c|c|c|c|c|c|c|}
\hline \multirow{3}{*}{$\begin{array}{c}\text { Parents } \\
\text { with } \\
\text { Winter } \\
\text { Morning } \\
\text { Phlegm }\end{array}$} & \multicolumn{6}{|c|}{ No. of Siblings } \\
\hline & \multicolumn{2}{|c|}{$\mathrm{Nil}$ or 1} & \multicolumn{2}{|c|}{2} & \multicolumn{2}{|c|}{3 or More } \\
\hline & $\begin{array}{l}\text { No. of } \\
\text { Children }\end{array}$ & $\begin{array}{c}\text { Prevalence } \\
(\%)\end{array}$ & $\begin{array}{l}\text { No. of } \\
\text { Children }\end{array}$ & $\begin{array}{c}\text { Prevalence } \\
(\%)\end{array}$ & $\begin{array}{l}\text { No. of } \\
\text { Children }\end{array}$ & $\begin{array}{c}\text { Prevalence } \\
(\%)\end{array}$ \\
\hline $\begin{array}{l}\text { Neither } \\
\text { One } \\
\text { Both }\end{array}$ & $\begin{array}{r}672 \\
122 \\
25\end{array}$ & $\begin{array}{l}14 \cdot 2 \\
16.5 \\
37 \cdot 9\end{array}$ & $\begin{array}{r}444 \\
137 \\
27\end{array}$ & $\begin{array}{l}11 \cdot 6 \\
28.6 \\
37.5\end{array}$ & $\begin{array}{r}464 \\
135 \\
52\end{array}$ & $\begin{array}{l}14 \cdot 8 \\
29 \cdot 4 \\
44 \cdot 4\end{array}$ \\
\hline
\end{tabular}

Table excludes 348 children owing to lack of data on cough, or on parents' smoking habits or morning phlegm, or on family size.

Younger school children tend to have higher prevalence rates for winter cough than older children (Colley and Reid, 1970). If the age distributions of children in the various groups in table II had not been the same prevalence rates between these groups might also have differed, but there were no differences in age structure between these groups of children.

Conclusions drawn from the evidence in this study need to be viewed with caution because it was not possible to collect evidence which would have excluded some other interpretation of the results. It was possible, for example, that the parents' account of their own symptoms might have influenced the answers they gave for their children and that the apparent association between parents and children in their respiratory experience could have been due to parents with symptoms over-reporting symptoms in their children. The children of parents who smoked may also have been more likely to have smoked than children of non-smoking parents, and this could have resulted in an increased prevalence of cough in such children. If either of these possibilities had oc- curred to any material extent it would have meant that, as given in table II the prevalence of cough in children from group 2 was too high in relation to cough in children from group 1 and that the prevalence of cough in children from group 3 was still higher. If the prevalence of cough in children from group 2 were to be reduced in order to correct for this and that of children from group 3 were to be corrected even more then the gradient shown in table II would probably become negative in that cough prevalence in children would have seemed to decline as more parents smoked. It therefore seems reasonable to conclude that the two possible qualifications to the data did not operate.

\section{Discussion}

Norman-Taylor and Dickinson (1972) in their study of children's respiratory infections and parental smoking habits reported higher prevalence rates for various indices of respiratory disease among children with parents who smoke. The present study, using a single index of respiratory disease, confirms their findings. It can now be seen, however, that a direct association exists between respiratory symptoms in parents and in their children. Parental smoking has a mainly indirect effect on the child by increasing the prevalence of the parents' respiratory symptoms and thus the prevalence of respiratory symptoms in their children. The direct effect on the children's respiratory symptoms of exposure to the smoke generated when their parents smoked cigarettes seemed to be relatively small.

The reason for the association between respiratory symptoms in parent and child is not clear. The sharing of genetic susceptibility between parents and children could have led to these similarities in respiratory disease, but this is unlikely to be the whole explanation, particularly in families where both parents smoke. There is, for example, no convincing evidence that adults who take up smoking have a greater genetic susceptibility to respiratory disease than non-smokers, and therefore there is no reason to suppose that susceptibility to respiratory disease would be different in the children of smokers and non-smokers. On the other hand, smoking parents differed from the nonsmokers in that they had higher prevalence rates for respiratory symptoms and the rates rose with the amount smoked, indicating some direct effect of smoking in causing their symptoms. In these circumstances the association between parents' and children's symptoms are more likely to be due to cross infection than to the sharing of genetic susceptibility.

If cross infection is indeed an important cause of respiratory symptoms in children of parents who smoke then there could well be some advantages for their children if the parents gave up the habit. In adults giving up smoking can result in a reduction in cough and expectoration and, therefore, in the chance of transmitting respiratory infections. Smoking parents, many of whom will not yet have developed severe or irreversible respiratory damage, can reasonably expect an improvement in symptoms if they give up the habit, and this would offer a promising way of reducing the risk of their children developing respiratory symptoms.

The findings in this paper need confirmation. This could be done by prevalence studies on a larger scale in other populations where, for example such aspects as the possible overreporting of symptoms could be adequately investigated. There is a need to investigate the likely benefit to the child from parents giving up smoking. Though passive inhalation of cigarette smoke by the child has not been shown to have an important effect in this series, this aspect should nevertheless be studied in infants and preschool children, who tend to be the most susceptible to respiratory infections. 
I thank Dr. J. J. A. Reid, who at the time of this study was County Medical Officer of Health, Buckinghamshire; Dr. A. W. Pringle, Aylesbury Area Medical Officer and Divisional School Medical Officer; the Buckinghamshire Education Department and the head teachers of the schools involved for their co-operation and help in this survey; Mrs. B. Hunt for the analysis of the data; Professor D. D. Reid who gave helpful advice in the preparation of this paper; and the field workers who included Mrs. B. Hunt, Miss S. J. Newby, S.R.N., Mrs. M. Pant, S.R.N., Miss J. P. E. Stocks, S.R.N., and Miss J. V. Tudhope, S.R.N.

\section{References}

Classification of Occupations (1970). (1972). Office of Population Censuses and Surveys, London, H.M.S.O.

Colley, J. R. T. (1970). Proceedings of the Third International Symposium on Bronchitis, ed. N. G. M. Orie and R. van der Lende, p. 8. Assen, Netherlands, Royal Van Gorcum.

Colley, J. R. T., and Reid, D. D. (1970). British Medical fournal, 2, 213.

Colley, J. R. T., and Reid, D. D. (1970). British Medical fournal, 2, 213. Memorial Fund Quarterly, 47, 215.

Krueger, D. E., Rogot, E., Blackwelder, W. C., and Reid, D. D. (1970). fournal of Chronic Diseases, 23, 411.

Norman-Taylor, W., and Dickinson, V. A. (1972). Community Medicine,

Todd, G. F. (1972). Statistics of Smoking in the U.K., 6th edn., London Tobacco Research Council.

\title{
Choreo-athetosis and Encephalopathy Induced by Phenytoin
}

\author{
D. L. MCLELLAN, M. SWASH
}

\section{Summary}

Two patients with intractable epilepsy who had been treated with various combinations of anticonvulsant drugs developed phenytoin encephalopathy. In both patients choreo-athetoid involuntary movements were prominent. Blood phenytoin concentrations were above $30 \mu \mathrm{g} / \mathrm{ml}$. When phenytoin was given in smaller doses and its level in the blood fell the involuntary movements and other clinical manifestations disappeared.

\section{Introduction}

Nystagmus, ataxia, dizziness, and drowsiness are well-known features of phenytoin toxicity which usually occur when the blood level is greater than $20 \mu \mathrm{g} / \mathrm{ml}$ (Buchthal et al., 1960). There have been few reports of other toxic effects on the central nervous system though Glaser (1973) pointed out that a reversible encephalopathy may occur in some patients treated with large doses of the drug. We describe two patients in whom choreo-athetoid involuntary movements were a prominent and presenting feature and in whom the involuntary movements and the encephalopathy were closely correlated with very high blood phenytoin concentrations.

\section{Case Reports}

CASE 1

A 31-year-old man who had attended hospital for many years for management of epilepsy was admitted for investigation of involuntary movements and intractable seizures. He had had a febrile convulsion when 2 years old and had had recurrent petit mal and major generalized seizures since he was 7. An electroencephalogram when he was aged 13 showed typical, generalized, three-per-second spike-and-wave complexes and diffuse bursts of theta and delta activity. When assessed for industrial training when aged 21 he had an I.Q. of 84 on the Wechsler Intelligence Scale. He was treated with various combinations of anticonvulsants,

\footnotetext{
Department of Neurology, Section of Neurological Sciences, London Hospital, London E1 1BB

D. L. MCLELLAN, M.B., M.R.C.P., Senior Registrar

M. SWASH, M.D., M.R.C.P., Consultant Neurologist
}

including troxidone, ethosuximide, primidone, and phenytoin, but he continued to have two or three major seizures a month. When he was aged 29 Hodgkin's disease was diagnosed by biopsy of an enlarged cervical lymph node. No involvement of liver, spleen, or para-aortic nodes was seen on laparotomy and he was treated with radiotherapy to the neck. There had been no recurrence. Treatment with phenytoin $300 \mathrm{mg}$, phenobarbitone $150 \mathrm{mg}$, and ethosuximide $750 \mathrm{mg}$ daily was continued. Two years later the seizures became more frequent (two to four a week) and primidone $750 \mathrm{mg}$, carbamazepine $800 \mathrm{mg}$, and phenytoin $450 \mathrm{mg}$ daily were gradually substituted for the previous treatment. During the next six weeks he complained of blurred vision and ataxia, leading to frequent falls. He continued to take the drugs. The seizures continued unchanged.

On admission to hospital he was slightly drowsy but orientated. Several minor seizures were observed. He had grade I nystagmus in all directions and upward conjugate gaze was impaired. There was generalized chorea which was present at rest and was enhanced by movement, particularly by walking. Slurred and hesitant speech seemed to be due to interposed choreic movements of the lips and tongue. In the outstretched upper limbs choreiform involuntary movements were accompanied by irregular postural lapses of the fingers, which were thought to be typical of asterixis rather than chorea. The gait was unsteady, but there were no cerebellar signs in the limbs. There was no weakness or sensory impairment, the tendon reflexes were brisk, and both plantar responses were flexor. Hyperplasia of the gums was noted. The increased frequency of seizures and the encephalopathy with involuntary movements were first ascribed to a degenerative or infective disorder associated with the Hodgkin's disease. The haemoglobin, white cell count, E.S.R., liver function tests, blood urea and electrolytes, skull and chest $x$-ray examinations, and brain scan were normal. The background activity in the E.E.G. was fragmented and slowed and there was an excess of diffuse, irregular delta activity of moderate voltage. Generalized atypical spike-and-wave activity was prominent. The blood phenytoin concentration was $37 \mu \mathrm{g} / \mathrm{ml}$.

The possibility of phenytoin encephalopathy was considered. The daily dose of phenytoin was reduced to $200 \mathrm{mg}$ daily and that of primidone increased to $1 \mathrm{~g}$. Carbamazepine $800 \mathrm{mg}$ daily was continued. During the next six days the patient became more alert, the chorea, ataxia, and nystagmus disappeared, and the blood phenytoin level fell to $16 \mu \mathrm{g} / \mathrm{ml}$. The seizures at first increased in frequency but then abated. Three weeks later he returned to work. Neurological findings at that time were normal.

\section{CASE 2}

This 15-year-old boy was referred for management of uncontrolled epilepsy. He had had frequent minor and major seizures since the age of 2 when he had presented in status epilepticus. He had been treated with varying combinations of phenytoin, phenobarbitone, ethosuximide, and sulthiame and had been almost free 